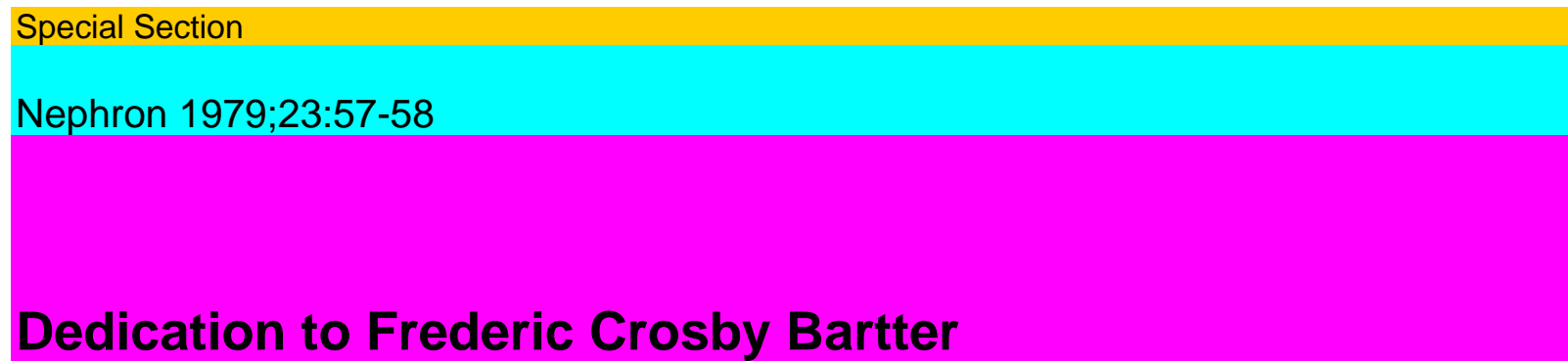

It is fitting and proper that Nephron should choose this time to pay tribute to Dr. Frederic C. Bartter, a man who has devoted most of his amazingly productive career to the investigation of interrelationships between the kidney and various hormones. 27 years ago, Dr. Bartter became the first Chief of the newly established Endocrinology Section of the National Heart Institute. This year he will retire from that position to become Professor of Medicine at the University of Texas, San Antonio, and Chief of Staff for Research at the Veterans Administration Hospital in San Antonio. During the intervening years, the Endocrinology Section has evolved and, more than once, has changed its name; so has the National Heart Institute. With only a few precious exceptions, the entire makeup of the NIH of 1951 has changed. Chiefs, assistants, directors, colleagues, and patients have all come and gone, but Dr. Bartter has remained steadfast in his leadership of the research unit he established to enhance our understanding of the roles of hormones in the pathogenesis of various aspects of cardiovascular and renal diseases.

What manner of man is Fred Bartter? Born into an ecclesiastical family, Fred grew up an intellectual perfectionist. Throughout his life, and that of his like-minded wife, Jane, there has never been the slightest compromise with excellence in education - education for themselves and for their children. It was inevitable that a man of Fred's talent and ambition should have been educated at Harvard College and Harvard Medical School, and that he should then have become the protege of the most brilliant clinical endocrinologist of his era, Dr. Fuller Albright. Like his mentor, Fred has always been an incisive thinker, able to cut through to the fundamental issues of a metabolic problem and arrive at powerful concepts of how endocrinologi-cal systems work in health and disease.

A fine example of the way these two men thought was their collaborative deduction that virilizing congenital adrenal hyperplasia is fundamentally a form of adreno-

cortical insufficiency, due to a metabolic error in the bio-synthetic pathway for cortisol. To compensate for the deficiency in cortisol secretion, they reasoned, the pituitary secretes excessive quantities of $\mathrm{ACTH}$, leading to excessive secretion of other classes of adrenal steroids. Bartter and Albright proved their thesis by treating affected patients with cortisone, thus correcting their hypersecretion of virilizing steroids. This, in my opinion, was the single greatest stroke of genius in the history of our attempts to understand and control this particular disorder. It was only one of several strokes of genius that have highlighted Dr. Bartter $1 / 8$ career. During his Harvard years, he collaborated with Dr. Alexander Leaf in studying the physiological consequences of simultaneous administration of antidiuretic hormone and water. These observations prepared his mind for his subsequent elucidation, with Dr. William B.Schwartz, of the 'inappropriate ADH syndrome', characterized by hyponatremia (often symptomatic and sometimes life-threatening in its severity) and inability to elaborate dilute urine. This clinical entity was thoroughly characterized in a trenchant series of clinical, experimental, and didactic papers over a period of two decades, and was shown to occur in a variety of patho-physiological settings. 
When 'electrocortin' (aldosterone) was discovered in 1953, it was immediately apparent to Dr. Bartter that this new hormone must be of critical importance in cardiovascular-renal physiology, and he turned his attention to the matters of determining its role in health and disease and ascertaining the factors controlling its secretion. Without neglecting the importance of other aldosterone regulatory factors, Dr. Bartter was responsible for the concept that extracellular fluid volume was a major determinant of aldosterone secretion. This reasoning ultimately led to the discovery that the aldosterone-regulatory influence of extracellular volume was mediated by the renin-angio-tensin system.

58

\section{Dedication to Frederic Crosby Bartter}

Yet another scientific contribution for which Fred will long be remembered was his discovery and elucidation of the syndrome of 'juxtaglomerular hyperplasia' with severe hyperreninemia, severe secondary aldosteronism, and severe hypokalemia - a condition now appropriately known as 'Bartter's syndrome'.

A survey of Dr. Bartter's 322 publications reveals a wealth of original research concerned with the endocrino-logical and metabolic aspects of renal function and malfunction; yet, great as his contributions to nephrology have been, it would be unjust to overlook the fact that he has also contributed generously to other aspects of clinical science. His achievements have been as broad as they have been deep.

It is to Fred's great credit that most of his scientific achievements have been shared with others. He has collaborated with over a 100 loyal friends, and in doing so he has enriched the lives and contributed to the scientific stature of each of them. Not only has Fred Bartter enjoyed an amazingly productive career, not only has he been the sole Chief of an important Branch of the National Heart, Lung, and Blood Institute since the very beginning of that organization, but he has also been a warm friend of innumerable scientists - scientists attracted by his ability to stimulate, to guide, to assist, and to enhance the talents of others.

Although this year marks the end of Fred Bartter's career as Chief of the HypertensionEndocrine Branch of the National Heart, Lung, and Blood Institute, it happily marks the beginning of a new career for him in San Antonio. His contributions to science and his association with eager colleagues will not end. It would be characteristic of him to experience a new burst of creativity. Like Tennyson's Ulysses he could say:

'Much have I seen and known

How dull it is to pause, to make an end

Some work of noble note, may yet be done

Come my friends,

Tis not too late to seek a newer world

To follow knowledge like a sinking star,

Beyond the utmost bound of human thought.'

Fred Bartter's countless friends wish him and his family well in their new career.

Dr. Grant W. Liddle, Professor of Medicine, Vanderbilt University School of Medicine, Nashville, TN 37332 (USA) 